\title{
Giant Lipoma: A Case Report
}

Mohammad Inam Zaroo, MBBS, MS, MCh,1 Sheikh Adil Bashir, MBBS, MS, MCh; ${ }^{2}$

Mir Mohsin, MBBS, MS, MCh;3 Peerzada Umar Farooq Baba, MBBS, MS, MCh; ${ }^{3}$

Syed Suraiya Arjumand Farooq, MD;4 Haroon Rashid Zargar, MBBS, MS, MCh ${ }^{2}$

${ }^{1}$ Associate Professor

${ }^{2}$ Assistant Professor

${ }^{3}$ Senior Resident

Department of Plastic and Reconstructive Surgery

${ }^{4}$ Senior Resident

Department of Chest Medicine

Sheri Kashmir Institute of Medical Sciences Medical College

Srinagar, Jammu and Kashmir, India

Abstract

A lipoma is a fatty tissue tumor presenting as a painless slowly growing mass that can affect any part of the body rich in adipose tissue. Lipomas can be present in the thigh, shoulder, trunk, etc, although they are usually small. We are reporting a 65-year-old man with a giant lipoma involving his left buttock and lumbar region.

Key words: Lipoma, benign tumors.

\section{Introduction}

\begin{abstract}
A lipoma is one of the most common benign mesenchymal tumors in the body and is composed of mature adipose cells. A lipoma can be found in almost all the organs ${ }^{1}$ of the body where fat normally exists, which is why it is also known as an ubiquitous tumor or universal tumor.2 While small superficial lipomas constitute simple surgical conditions, large and deep lipomas represent a real diagnostic and therapeutic challenge. ${ }^{3}$ Presentation is usually as a painless subcutaneous swelling. Other presentations depend on the site and size of the lesion and on local pressure effects.
\end{abstract}

\section{Case Report}

A 65-year-old male patient presented with complaints of swelling in the left gluteal region and a dull ache in left lower limb for the past three years. Examination revealed a large mass in the left gluteal

Correspondence should be directed to

Mir Mohsin, MBBS, MS, MCh

e-mail:m_mohsin@rediffmail.com region, extending to the left lumbar region, which was nontender, soft in consistency, noncompressible with well-defined margins (Figure 1). The swelling was not fixed to the skin or underlying structures.

Fine needle aspiration cytology (FNAC) of the swelling revealed mature fat cells suggestive of a lipoma. An X-ray revealed a soft tissue swelling with normal bone. A magnetic resonance imaging (MRI) scan revealed a well-circumscribed soft tissue swelling with septations, raising the suspicion of malignant transformation. The MRI delineated the extent of the tumor and revealed its relation to the adjacent structures. Thus it helped in planning the incision and operation.

The patient was positioned in a right lateral decubitus position under general anesthesia with orotracheal intubation. After adequate preparation and draping, a lazy incision was made over the swelling, extending from the upper to the lower extent of the tumor. Careful dissection was carried out. A part of the tumor was found under the gluteal muscles. Important neurovascular structures including the sciatic nerve and gluteal vessels were identified and preserved. The tumor was dissected out and 


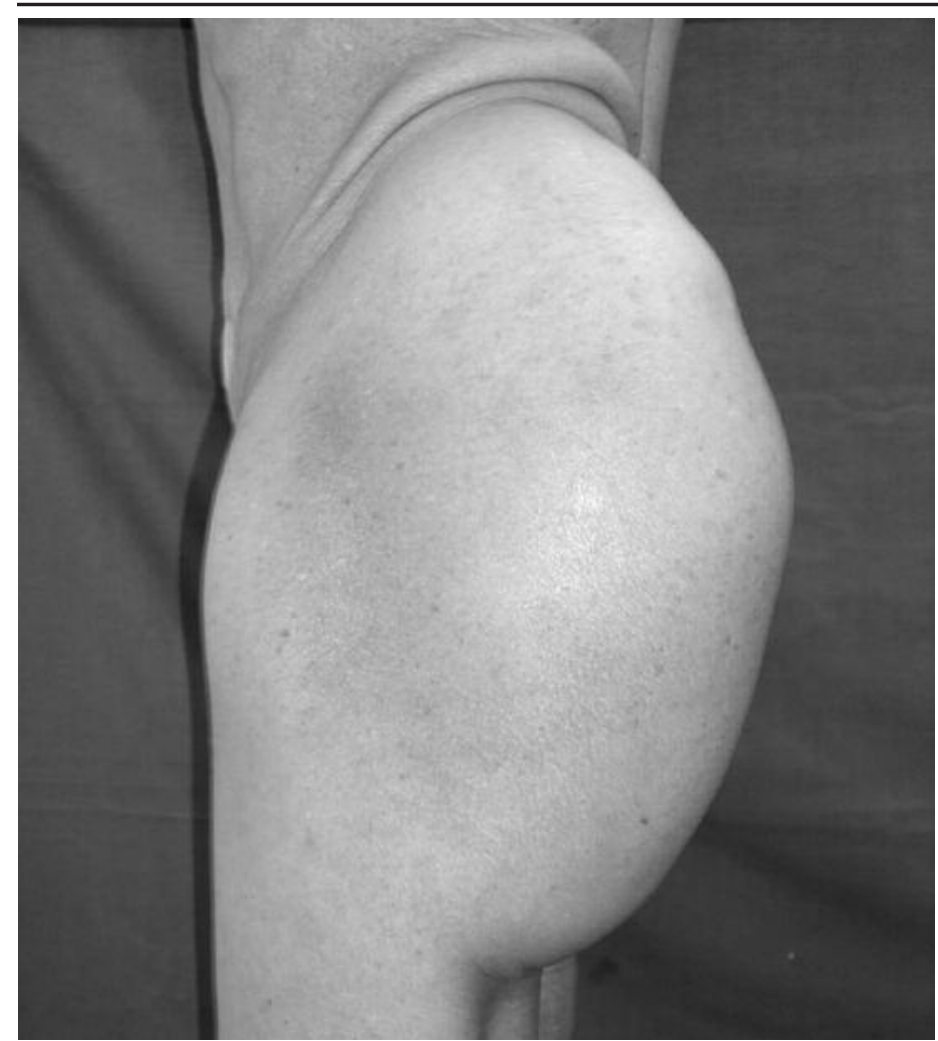

Figure 1. The large mass in the left gluteal region extending to the left lumbar region.

excised en masse. The tumor measured $32.5 \times 21 \mathrm{~cm}$ (Figure 2) and weighed $3.2 \mathrm{kgs}$. The wound was closed in layers over a suction drain. A histopathological examination revealed features consistent with a lipoma with no evidence of any malignant transformation. The postoperative period was uneventful.

\section{Discussion}

A solitary lipoma is the most frequent soft tissue tumor, often appearing between 40 and 60 years of age. ${ }^{4}$ For a lipoma to be referred to as "giant," it should be at least $10 \mathrm{~cm}$ in diameter or weigh a minimum of 1000 grams $, 4,5$ as was the case in our patient. Its volume is the source of a good many social life problems (keeping the lipoma discreet in clothing, difficulties in dressing) and causes multiple health problems such as pain, difficulties in sleep, compression of nerves or vital structures, infections, etc. ${ }^{5}$

Only rarely are children affected. Lipomas may be single or multiple. Multiple lipomas are more common in women, many are seen in a familial setting. ${ }^{5}$

Diagnosis is primarily clinical, but malignancy has to be ruled out. In addition to FNAC, MRI' ${ }^{6}$ has

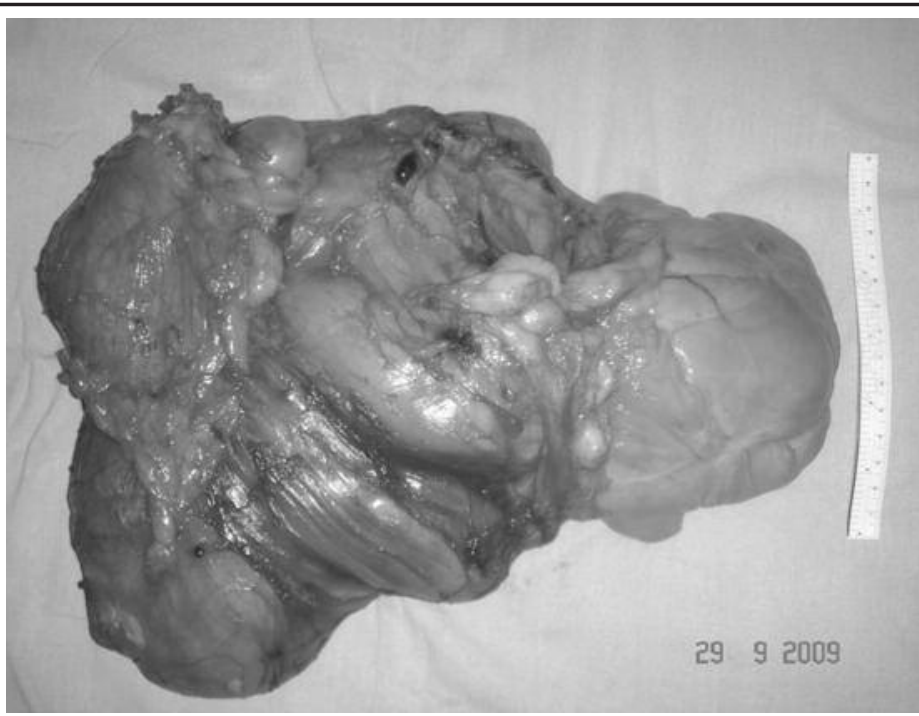

Figure 2. The tumor excised en-mass measured 32.5 $\mathrm{x} 21 \mathrm{~cm}$.

been well established to aid in arriving at a diagnosis and planning for surgery. Features that suggest malignancy include old age, large size, presence of thick septa, presence of nodular and/or globular or nonadipose mass-like areas, and decreased percentage of fat composition. ${ }^{7}$ Many of these factors were present in our case.

Johnson et al suggested that any soft tissue tumor that is greater than $5 \mathrm{~cm}$, should be considered malignant until proved otherwise. 8 In our case, the size of the tumor was $>5 \mathrm{~cm}$, but histopathology revealed a benign lesion.

Surgical excision is the treatment of choice because these large tumors may undergo malignant transformation. ${ }^{3}$ Another option for treatment of these giant tumors is liposuction, ${ }^{9}$ which was not considered in our case both because the patient did not give the consent and because of the possibility of malignant transformation. In our case, the primary concerns of the patient were the discomfort and dragging pain and the apprehension of malignancy, which were relieved completely after surgery. The preoperative findings and histopathological features confirmed the diagnosis of benign giant lipoma. These tumors have a tendency for recurrence, and the patients should be kept under a regular followup.

\section{Conclusion}

The presentation of a long-standing giant lipoma may resemble a malignant lesion. Surgical excision is the treatment of choice to alleviate the symptoms 
and the apprehension of malignancy and provides tissue diagnosis.

\section{References}

1. Devis C Jr., Gruhn JG. Giant lipoma of the thigh. Arch Surg. 1967;95:151. http://doi.org/g36

2. Hafeez A, Darzi A, Zargar HR, et al: Giant lipoma. The Internet Journal of Plastic Surgery. 2007;4(2). http://www.ispub.com/journal/ the internet journal of plastic surgery/volume 4 number 2 40/article/giant lipoma.html

3. Hussain A, Mahmood H. Ulcerated giant lipoma of the right thigh. The Internet Journal of Surgery. 2007;11(1). http://www.ispub.com/journal/ the internet journal of surgery/volume 11 num ber $1 /$ article/ulcerated giant lipoma of the right thigh.html

4. Verdin V, Preud'Homme L, Lemaire V, et al. [Giant lipoma on the back]. Rev Med Liege. 2009;64:414-7. PubMed PMID: 19777924
5. Mazzocchi M, Onesti MG, Pasquini P, et al. Giant fibrolipoma in the leg - a case report. Anticancer Res. 2006;26:3649-54. $\quad$ Pubmed PMID: 17094380 http://ar.iiarjournals.org/ content/26/5B/3649

6. Sundaram M, Baran G, Merenda G, et al. Myxoid liposarcoma: magnetic resonance imaging appearances with clinical and histological correction. Skeletal Radiol. 1990;19:359-62.

http://dx.doi.org/10.1007/BF00193091

7. Kransdorf MJ, Bancroft LW, Peterson JJ, et al. Imaging of fatty tumors: distinction of lipoma and well-differentiated liposarcoma. Radiology. 2002; 224:99-104.http://doi.org/g37

8. Johnson CJ, Pynsent PB, Grimer RJ. Clinical features of soft tissue sarcomas. Ann R Coll Surg Engl. 2001;83:203-5. PubMed Central PMCID: PMC2503577

9. Nichter LS, Gupta BR. Liposuction of giant lipomas. Ann Plast Surg. 1990;24:362-5. PubMed PMID: 2533787 